\title{
Connection between Ocean Acidification and Sound Propagation
}

\author{
Cem Gazioğlu ${ }^{*}$, A. Edip Müftüoğlu', Volkan Demir ${ }^{1}$, Abdullah Aksu², Volkan \\ Okutan $^{1}$
}

\author{
${ }^{1}$ Istanbul University, Institute of Marine Sciences and Management, Department of Marine Environment, BERKARDA \\ Remote Sensing and GIS Laboratory, 34134, ISTANBUL-TR \\ ${ }^{2}$ Istanbul University, Institute of Marine Sciences and Management, Department of Chemical Oceanography, 34134, \\ ISTANBUL-TR
}

\begin{abstract}
Ocean Ambient Noise (OAN) results from both anthropogenic and natural sources. Varied noise sources are dominant in low (LFB: 10 to $500 \mathrm{~Hz}$ ), medium (MFB: $500 \mathrm{~Hz}$ to $25 \mathrm{kHz}$ ) and high (HFB:>25 kHz) frequency bands. Mostly, LFB is dominated by anthropogenic sources. MFB that cannot spread over long ranges of sound sources contribute to the OAN. Ocean is an exceptionally noisy place.

Ocean acidification $(\mathrm{OAc})$ from rising Carbon dioxide $\left(\mathrm{CO}_{2}\right)$ levels will result in decreased sound absorption and therefore, amplified levels of OAN. Carbon dioxide spewed into the atmosphere by burned fossil-fuel which dissolves in the seawater causes more acidic condition in oceans which has strong connection between chemical oceanography and sound propagation. As the ocean becomes more acidic, sound absorption at LFB decreases and acidic oceans would result in significant decreases in ocean sound absorption.

In the recent years, the acoustic environment of oceans has reacted to transformations in both natural and anthropogenic impacts. Greenhouse gases concentrations, especially $\mathrm{CO}_{2}$, rises in atmosphere due to industrial revolution. $\mathrm{CO}_{2}$ dissolved in the seawaters deposited in two major forms (carbonate and bicarbonate), which both lead to decrease $\mathrm{pH}$ of surface waters. Over the last 400 million years, $\mathrm{pH}$ of oceans has been stable around 8.2 globally. Latest investigations suggest that global $\mathrm{pH}$ is around 8.1 globally and various general oceanic circulation models (GOCM) calculate that, emissions could reduce ocean $\mathrm{pH}$ by a degree between 0.4 units (according to moderate approach) and 0.7 units (according to an aggressive one) by the end of this century.

This article discusses the $\mathrm{CO}_{2}$ considerations both in the atmosphere and hydrosphere which are directly related with seawater $\mathrm{pH}$ and oceans noise levels.
\end{abstract}

Keywords: Ocean Acidification $(\mathrm{OAc}), \mathrm{pH}, \mathrm{CO}_{2}$, sound propagation, carbonate or bicarbonate.

\section{Introduction}

Since the industrial revolution, the soundscape of the marine environment has responded to the changes in anthropogenic impacts. A soundscape is a combination of sounds that characterize and describe an ocean environment, as known as acoustic ecology. The idea of a soundscape covers the natural acoustic environment and anthropogenic sounds. The disruption of the natural acoustic environment which is categorized by spatial and temporal capriciousness will be caused by the anthropogenic noise pollution (Etter, 2012). Ocean ambient noise (OAN) is one of the important features of marine life forms
(Richardson et al. 1995, Halpern et al. 2008). Sound is an extremely proficient way to propagate energy through the ocean and most marine life forms exploit this property. Fish utilize sound especially for navigation, surviving, procreation and communication (Bass and McKibben 2003, Simpson et al. 2005). Marine mammals use sound as a primary means for underwater navigation, communication, hunting and sensing (Ketten and Wartzok 1999; Hildebrand, 2009). In the last years, the acoustic environment of oceans has reacted to transformations in both natural and anthropogenic impacts. The climate change, which is mostly driven by 
anthropogenic affects, influences the ocean soundscape.

Atmospheric concentration of $\mathrm{CO}_{2}$ billowed 200-300 parts per million (ppm) over the last 400000 years and by the middle of 1700's it has been approaching $397 \mathrm{ppm}$ as a result of the anthropogenic factors (Fig 1). Since the beginning of the industrial revolution, the release of $\mathrm{CO}_{2}$ from anthropogenic activities has resulted in an increase in atmospheric $\mathrm{CO}_{2}$ concentrations from 280 to $397 \mathrm{ppm}$. Approximately $50 \%$ of this increase has been occurred since 1990's. Carbon dioxide concentration is now higher than it has ever been for more than 800,000 years (Luthi et al., 2008). Some aggressive climate and/or atmospheric models reports that atmospheric $\mathrm{CO}_{2}$ levels could approach $800 \mathrm{ppm}$ near the end of the century (Friedlingstein et al., 2006).

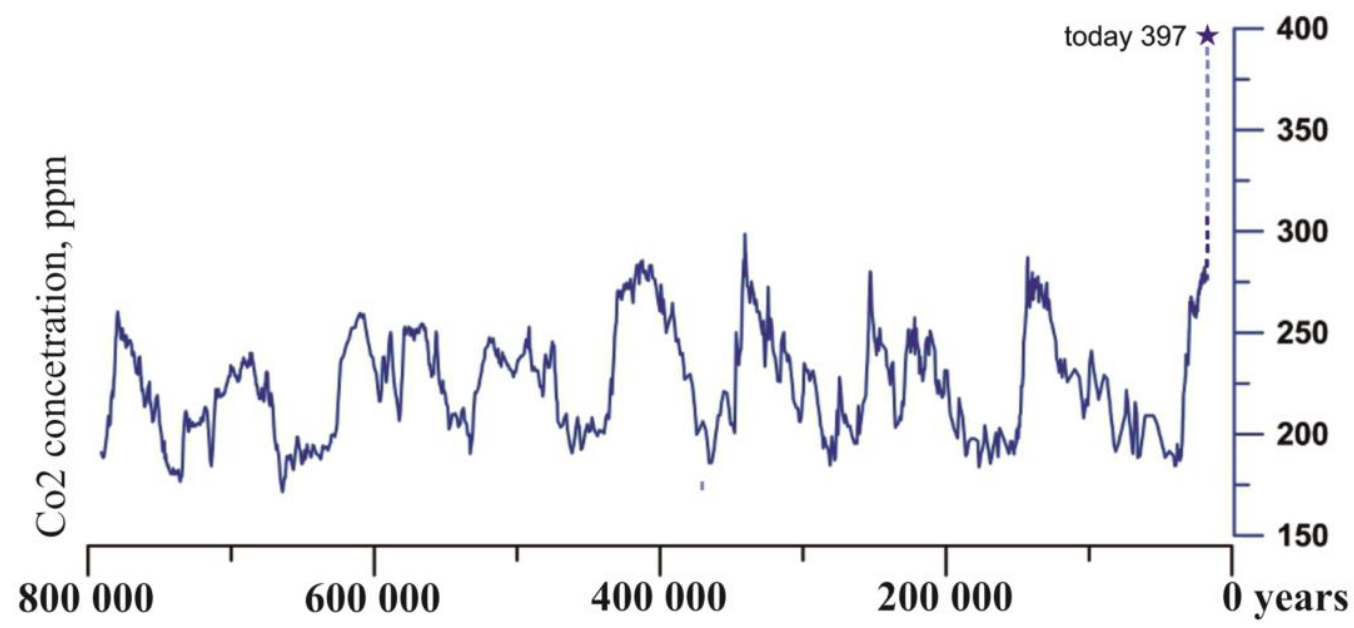

Fig.1. $\mathrm{CO}_{2}$ concentration as measured in atmosphere (modified from Lüthi et al., 2008).

The oceans are a natural carbon sink, which absorbs $\mathrm{CO}_{2}$ from the atmosphere. However anthropogenic $\mathrm{CO}_{2}$ in the ocean could not be directly measured, but several approaches have been done (Wallace 2001; Lo Monaco et al., 2005; Waugh et al., 2006; Sabine and Felly, 2007). Concentration of rising greenhouse gases due to the industrial revolution has caused in atmosphere the greatest $\mathrm{CO}_{2}$ concentration. Currently oceans absorbs $\% 25$ of human created $\mathrm{CO}_{2}$ emissions. $\mathrm{CO}_{2}$ mixes with the seawater, mainly either as carbonate $\left(\mathrm{CO}_{3}{ }^{-2}\right)$ or bicarbonate $\left(\mathrm{HCO}_{3}{ }^{-}\right)$forms and both of them lead to higher acidity of surface waters. $\mathrm{CO}_{2}$ will react with seawater and progress to $\mathrm{CO}_{2}$ (aqua) $0.5 \%$, bicarbonate $89.0 \%$ and carbonate $10.5 \%$. The oceans get more acidic as excess $\mathrm{CO}_{2}$ spewed into the atmosphere. The oceans have already become $\% 30$ more acidic than before the industrial revolution. Over the last 400 million years, $\mathrm{pH}$ of oceans has been stable around $8.2 \pm 0.3$ (local, regional and seasonal variations) globally. Latest investigations suggest that global $\mathrm{pH}$ is close about 8.1 globally and various general oceanic circulation model (GOCM) calculate that by the end of this century, emissions could reduce ocean $\mathrm{pH}$ by 0.4 units (moderate approach) or 0.7 units (aggressive one) globally (Fig.2) According to Henry's law, an increase in the atmospheric level of $\mathrm{CO}_{2}$ increases the concentration of $\mathrm{CO}_{2}$ in the surface water of the oceans.

Higher absorption will result in a smaller propagation gain which means that at a given distance from a source the sound level will be louder than it was. This article discusses the $\mathrm{CO}_{2}$ considerations both in the atmosphere and hydrosphere which directly related with the seawater $\mathrm{pH}$ and oceans noise levels. Figure 2 indicates the past and the contemporary variability of $\mathrm{pH}$. Future predictions are model derived values based on IPCC mean scenarios (Turley et al., 2006). 


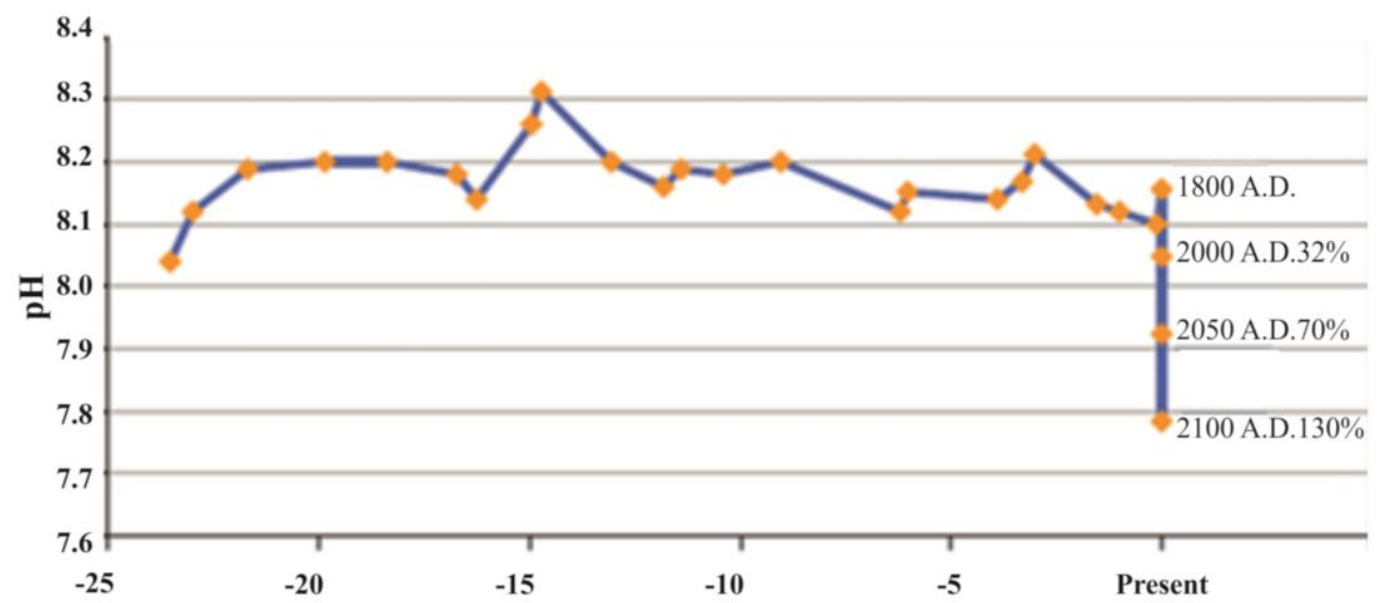

Fig. 2. Future calculations are derived values based on IPCC mean scenarios, date and $\%$ increase in $\mathrm{H}^{+}$ions (modified from Turley et al., 2006).

\section{Ocean Acidification}

Anthropogenic activities have led to a new flux of $\mathrm{CO}_{2}$ into the atmosphere. Carbon dioxide in the atmosphere is a chemically unreactive gas but, when dissolved in seawater, becomes more reactive and takes part in several chemical, physical, biological and geological reactions, many of which are complex (Raven et al., 2005). According to Raven and Falkowski (1999) approximately \%45 has remained in the atmosphere; most of the rest has been taken up by the oceans. According to Sabine and Feely (2007) and Canadell et al. (2007) over the industrial era, the ocean has absorbed about one-quarter of anthropogenic carbon emissions which is about $8.8 \pm 1.35$ billion metric tons/yr. This absorption has benefited humankind by significantly curtailing the growth of $\mathrm{CO}_{2}$ levels in the atmosphere, thereby reducing the global warming which has been realized to date.

The carbon in the ocean is a mixture from both natural and anthropogenic sources. The anthropogenic fraction comes from humaninduced emissions of $\mathrm{CO}_{2}$ into the atmosphere that have continued at an increasing rate since the start of the industrial revolution and in 2007 was approaching $10 \times 10^{15}$ grams $\mathrm{CO}_{2}$, which is equal to $10^{9}$ metric tons of $\mathrm{C}$ (Canadell, et al., 2007). It is estimated that $30 \%$ of total anthropogenic emissions annually are taken up from the atmosphere and sequestered by the ocean (Sabine and Feely, 2007). Regardless of source (natural or anthropogenic) the carbon in the ocean follows the ocean carbon cycle as described Fig. 3.

$\mathrm{CO}_{2}$ dissolved in ocean occurs in three (aquatic $\mathrm{CO}_{2}$, carbonate and bicarbonate) inorganic forms, with the contribution of each forms being dependent on $\mathrm{pH}$. Bicarbonate is the most common inorganic carbon form in the ocean (see following equations [1]).

$\mathrm{CO}_{2 \text { (atmos) }} \leftrightarrow \mathrm{CO}_{2(\mathrm{aq})}+\mathrm{H}_{2} \mathrm{O} \leftrightarrow \mathrm{H}_{2} \mathrm{CO}_{3} \leftrightarrow \mathrm{H}^{+}+\mathrm{HCO}_{3}^{-}$ $\leftrightarrow 2 \mathrm{H}^{+}+\mathrm{CO}_{3}^{-2}[1]$

Also carbon cycle could be described as the fluxes of $\mathrm{CO}_{2}$ between the oceans, terrestrial, biosphere, lithosphere and the atmosphere in oceanography. The principal effect of adding fossil fuel $\mathrm{CO}_{2}$ to sea water is a loss of carbonate ion to form bicarbonate and reduce $\mathrm{pH}[2]$.

$$
\mathrm{CO}_{2}+\mathrm{H}_{2} \mathrm{O}+\mathrm{CO}_{3} \rightarrow 2 \mathrm{HCO}_{3}^{-}[2]
$$

The addition of fossil fuel $\mathrm{CO}_{2}$ alone could not change alkalinity of oceans. According to Redfield (1934) ratio (atomic ratio of C:N:P 106:16:1), the decline in dissolved oxygen that is simply associated with lower solubility of the gas in warmer water will not reduce $\mathrm{pH}$; but by far the superior portion of the variations now being observed is from reduced ventilation respiration and this is necessarily accompanied by an increase in dissolved $\mathrm{CO}_{2}$. The addition from the decomposition reaction of respiratory $\mathrm{CO}_{2}$ at depth is accompanied by changes in the oxidation state of the nitrogen species, and this will change alkalinity and reduce ocean 
buffering capacity (Brewer and Goldman, 1976), thus $\mathrm{pH}$ change over addition of $\mathrm{CO}_{2}$ which is not only the result of fossil fuels but also deposition of reactive sulfur and nitrogen primarily affect the surface and coastal waters of ocean.

Oceans ecosystems play an important role in the global carbon cycle which involves both organic compounds and inorganic carbon compounds $\left(\mathrm{CO}_{2}\right.$ and carbonates). Inorganic compounds are in many forms of $\mathrm{CO}_{2}$ present in oceans. $\mathrm{CO}_{2}$ is soluble in water and it reacts with water and forms a balance of several ionic and non-ionic species which are dissolved as free $\mathrm{CO}_{2}$, carbonic $\mathrm{H}_{2} \mathrm{CO}_{3}, \mathrm{HCO}_{3}-$ and carbonate $\left(\mathrm{CO}_{3}{ }^{2-}\right)$. These different forms of dissolved inorganic carbon are transferred from an ocean's surface. Basic describe of OAc could be explained as dissolving $\mathrm{CO}_{2}$ in seawater caused acidification in oceans by decreasing ocean $\mathrm{pH}$ which driven by increasing the hydrogen ion $(\mathrm{H}+)$ concentration in it [3].

$\mathrm{CO}_{2}+\mathrm{H}_{2} \mathrm{O} \leftrightarrow \mathrm{H}_{2} \mathrm{CO}_{3} \leftrightarrow \mathrm{HCO}_{3}{ }^{-}+\mathrm{H}^{+} \leftrightarrow \mathrm{CO}_{3}{ }^{2-}+2 \mathrm{H}^{+}[3]$

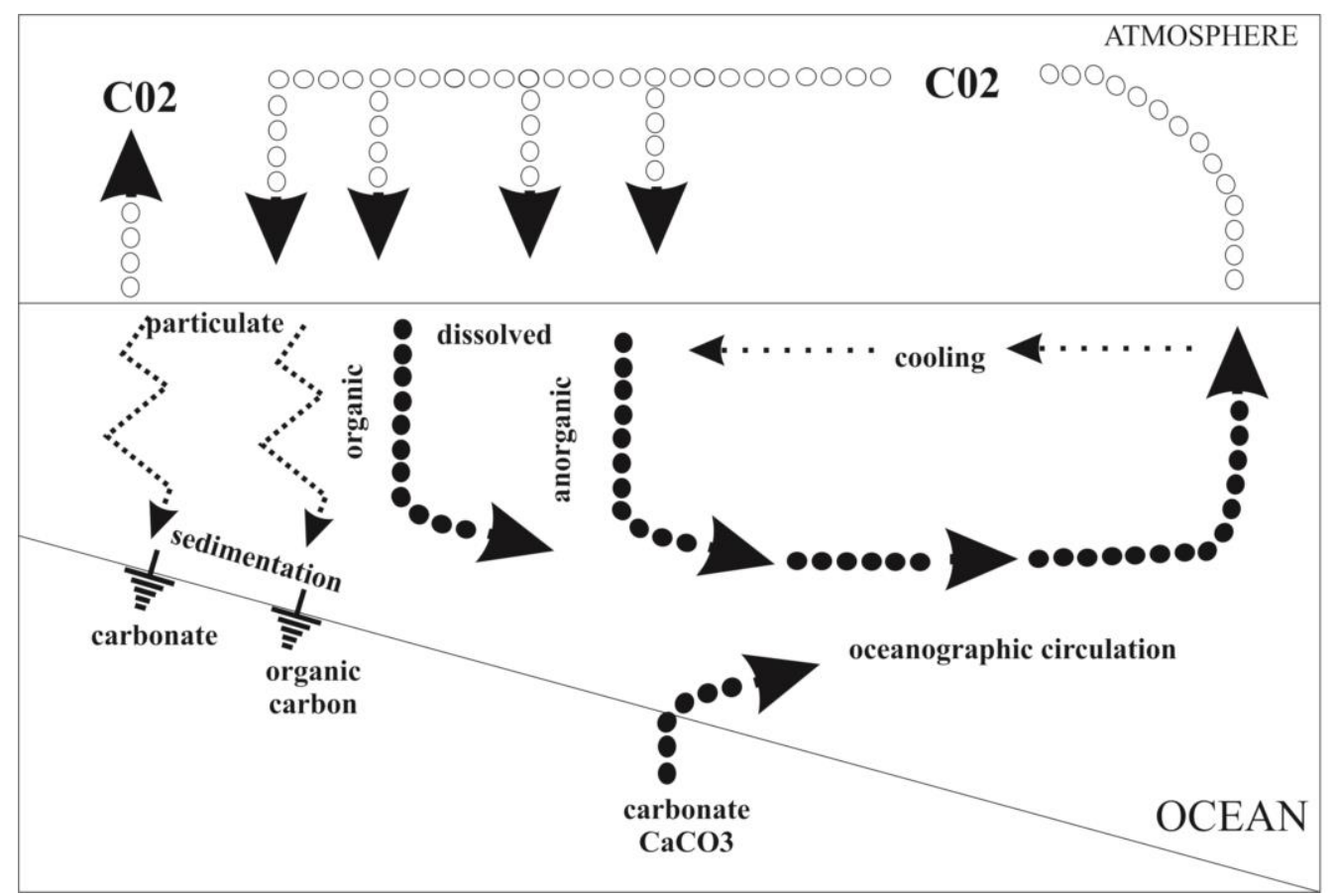

Fig. 3. Carbon circle.

These atmospheric additions of acids change ocean alkalinity and $\mathrm{pH}$, and while there are offsetting reactions the net effect is acidification (Doney et al., 2007). Otherwise, $\mathrm{CO}_{2}$ is absorbed by seawater, chemical reactions occur that reduce seawater $\mathrm{pH}$, carbonate ion concentration and saturation states of the biologically important $\mathrm{CaCO}_{3}$ minerals calcite and aragonite in a process commonly referred to as OAc (Broecker and Clarke, 2001; Caldeira and Wickett, 2003, 2005; Orr et al., 2005; Doney et al., 2009).

Earth's atmospheric concentration of $\mathrm{CO}_{2}$ is expected to continue to rise at an accelerating rate, leading to significant temperature increases in the atmosphere and the surface ocean in the coming decades. Between middle of 1700's and 1994 globally surface ocean pH was estimated to have decreased from approximately 8.25 to 8.14 (Jacobson, 2005) on behalf of an increase of $\% 30$ in $\mathrm{H}^{+}$ion concentration in the oceans (Hall-Spencer, et al., 2008). Carbonate ion concentration declines, however, because of the increasing $\mathrm{H}^{+}$ concentrations. Oceans are now undergoing an extraordinary transition in their fundamental chemical state and at a rate not seen since last 800000 years. The belongings are being felt not only in biological impacts but also on ocean acoustics (Hester et al., 2008). The pH of seawater has decreased by 0.1 since the 
beginning of the industrial era. The projected $0.3-0.4 \pm \% 0.5 \mathrm{pH}$ drop for the 21 st century is equivalent to approximately a $\% 150 \pm \% 15$ increase in $\mathrm{H}+$ and $\% 50 \pm \% 5$ decrease in $\mathrm{CO} 3$ 2 concentrations (IPCC, 2005; Caldeira and Wickett, 2003, 2005; Orr et al., 2005), with a decrease approximately $0.0018 \mathrm{pH}$ units/yr over the last quarter century (Bates, 2007; Bates and Peters, 2007; Santana-Casiano et al., 2007; Dore et al., 2009). According to Friedlingstein et al., (2006) by the middle of this century, atmospheric $\mathrm{CO} 2$ levels could reach more than $500 \mathrm{ppm}$, and exceed $800 \mathrm{ppm}$ by the end of the century. Additionally, burning of fossil fuels results not only in increasing $\mathrm{CO}_{2}$ emissions but also in accumulating of reactive sulfur ( 0.8 $\mathrm{Tmol} / \mathrm{yr})$ and nitrogen $(2.7 \mathrm{Tmol} / \mathrm{yr})$ mainly in the surface waters of oceans (Doney et al., 2007). These chemical additions of strong acids

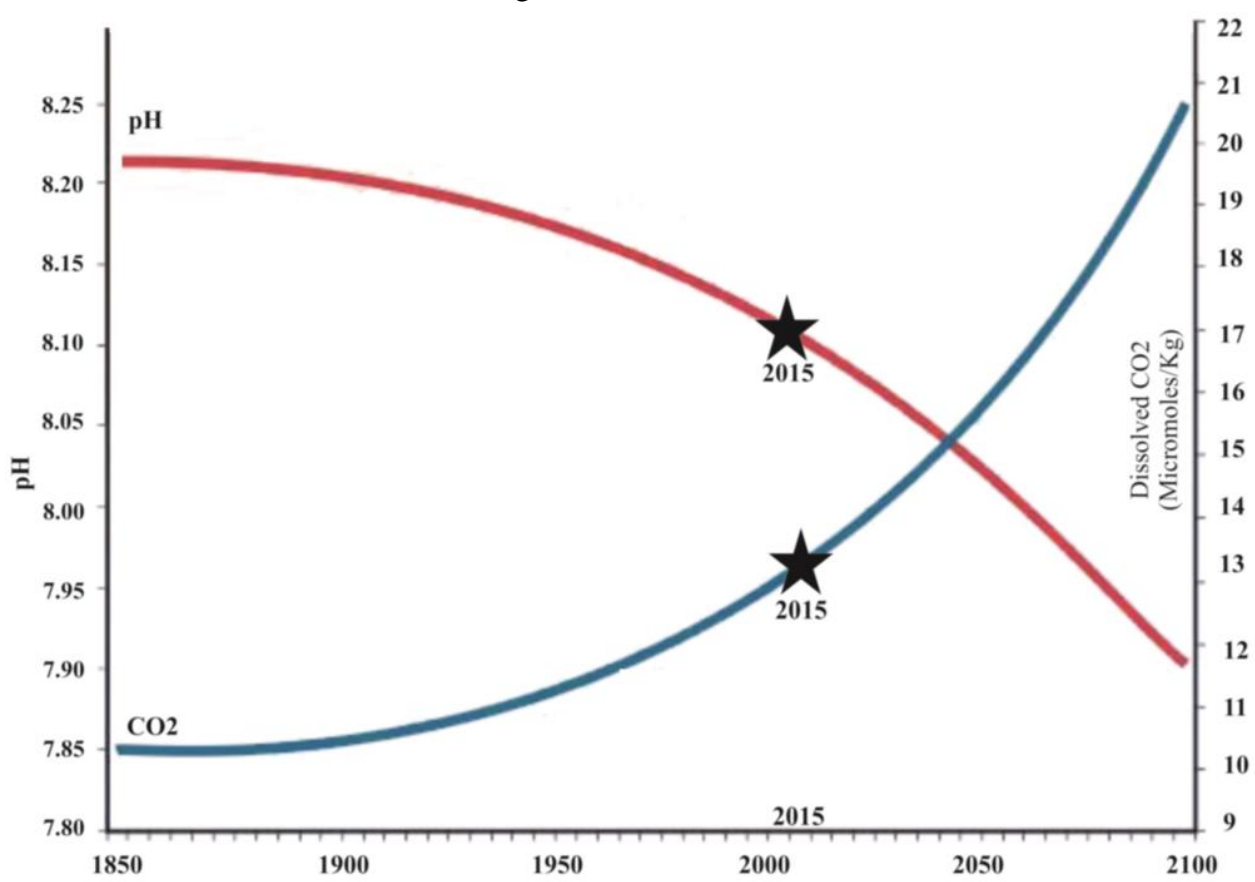

Fig. 4. Historical and Projected pH and Dissolved CO2 (modified from Feely, et al. 2006) change $\mathrm{pH}$, and while there are counterbalancing feedbacks the net result is OAc.

Nowadays, $\mathrm{pH}$ is around 8.1. Oceanic General Circulation Model (OGCM) shows that by the end of this century, emissions would reduce ocean $\mathrm{pH}$ by another 0.5 units dramatically. As a result of increasing anthropogenic loads, it is estimated to drop by a further minimum 0.3 todays units, 0.4 from pre-industrial, by 2100 , which represents an increase in the ocean's hydrogen ion $(\mathrm{H}+)$ concentration by approximately 2.5 times relative to the beginning of the industrial era. It is estimated to drop by a further minimum 0.4 and 0.7 maximum $\mathrm{pH}$ units (Fig.4.).
Results from $\mathrm{CO}_{2}$ surveys and time-series studies over the past two decades show that $\mathrm{OAc}$ is a predictable consequence of rising atmospheric $\mathrm{CO}_{2}$ (Feely et al., 2004; Bates and Peters, 2007; Santana-Casiano et al., 2007; Dore et al., 2009; Takahashi et al., 2009) that is independent of the uncertainties and outcomes of climate change. Seawater carbonate chemistry is governed by a series of abiotic chemical reactions $\left(\mathrm{CO}_{2}\right.$ dissolution, acid/base chemistry) and biologically mediated reactions (photosynthesis, respiration, and $\mathrm{CaCO}_{3}$ precipitation and dissolution). The first key reaction occurs when $\mathrm{CO}_{2}$ gas from the atmosphere dissolves into seawater 


\section{Ocean Ambient Noise (OAN)}

Carbon dioxide, which is directly anthropogenic activities by the global ocean, induces major changes in oceans chemistry that could have dramatic impacts on both biological ecosystems in the ocean surface and it will be the cause of the increased OAN (Felly, et al., 2009). According to Intergovernmental Panel on Climate Change (IPCC) reports further compounding the problem is the globally observed change in ocean surface temperatures. It is estimated that the ocean surface is now about approximately $0.7^{\circ} \mathrm{C}$. The effects of rising temperatures do not only affect the ocean surface, but these higher temperatures propagate through new stratification which is investigated in detailed and the effects of these phenomena in underwater environments which are explained and understood. Ocean acidification is located on a secondary emphasis for marine acoustic environment. Underwater sound propagation is much more complex; mainly it depends on spatial distribution of sound sources and environmental parameters. However, increasing $\mathrm{pH}$ and temperature are not the main factors and only responsible for changes in the absorption mechanism, but they are also contributing to increase OAN.

Ocean Ambient Noise is the result of both natural and anthropogenic sources. Natural sources are well known as earthquakes, waves, rainfall, bio-acoustic sound generation, etc. Anthropogenic noise is produced by different activities (shipping; oil and gas exploration, naval operations, fishing, research, construction, icebreaking, boating, military and civil sonars, etc.) (Hildebrand, 2009). According to Ross (1993), OAN increased by about ten decibels between 1950 and 1975 . Additionally, according to Kuperman (1988) ocean environmental factors that are important for acoustic propagation and thereby influence OAN are; the sound speed structure of the ocean for long range propagation, the acoustic attenuation of seawater, the water depth and the geo-acoustic properties of the ocean bottom. Sound velocity in the ocean is accepted 1500 $\mathrm{m} / \mathrm{sec}$., it is actually dependent on many parameters such as ambient temperature, salinity and depth $(1400 \leq$ Velocidity of Sound $\leq 1700 \mathrm{~m} / \mathrm{sec}$.) (Fig.5.)

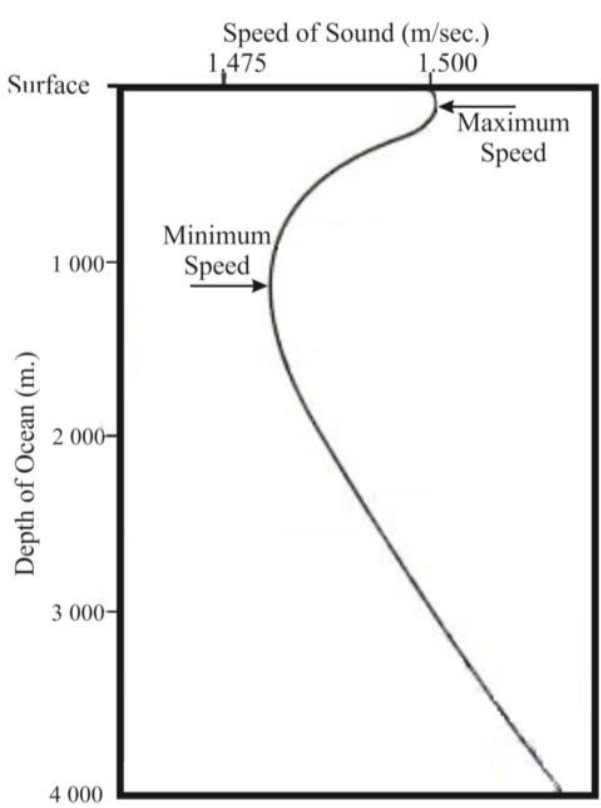

Fig. 5. Sound speed varies as a function of water depth. The speed of sound in water increases with increasing water temperature, increasing salinity and increasing pressure (related with depth).

Alkalinity dependence of sound absorption in the ocean has been drawn attention by Fisher and Simmons (1977) and has been linked to ocean geochemical and carbon cycles by Brewer et al. (1995). The emerging impacts of the fossil fuel $\mathrm{CO}_{2}$ and climate-induced changes on sound absorption in the ocean are studied to understand by oceanographers. Sound absorption depending on the ocean alkalinity which will drop by another $0.6 \mathrm{pH}$ units, the absorption of $200 \mathrm{~Hz}$ sound would decrease by up to $\% 70$ already during this century considering the atmospheric composition, gases from the atmosphere to the oceans and anthropogenic activities.

Specifically $\mathrm{CO}_{2}$ spewed into the atmosphere by burning of the fossil-fuel dissolves into the sea causes more acidic condition in oceans which as a strong connection between chemical oceanography and sound propagation. An acoustic environment is a mixture of sounds that characterizes, or arises from, an ocean environment. One of the most important effects of the obscured effects of climate change is $\mathrm{OAc}$ from which fossil fuel $\mathrm{CO}_{2}$ invasion and reduced ventilation will result in significant 
decreases in ocean sound absorption for frequencies lower than about $10 \mathrm{kHz}$ (Herster, et al., 2008). More acidic seawater will cause increasing noise level in ocean and lowfrequency sounds will propagate farther, making the ocean noisier. The major changes are projected and expected to happen in the ocean surface waters. Obviously ocean surface will be affected more strongly than the rest of ocean.

Sound could travel farther at depth of about $1000 \mathrm{~m}$ than at the surface. Although most of the anthropogenic and natural sources of sounds are scattered from ocean surface, they also could reach the depth of oceans and travel over thousands of kilometers in the ocean. The speed of sound depends on the temperature of water, salinity and the pressure which is related column height (Fig 5). Sound that does not hit the ocean surface or seafloor will still lose energy to absorption which increases as the frequency of the sound increases and higher frequency sounds are therefore only detectable at shorter distances. The distances at which sounds can be detected depend on the frequency, how loud the source is, and how loud the OAN is.

In LFB and MFB sound absorption has already decreased by $\% 15 \pm \% 5$ as OAc increase (decrease of $\mathrm{pH}$ ). This means that sound travels $\% 15 \pm \% 5$ further, with the effect that OAN levels rise as the cumulative noise in any one place contains source noise from a larger area. The most dramatic impact is in sound below $1 \mathrm{kHz}$, with significant effects up to $10 \mathrm{kHz}$ (Hester et al., 2008).

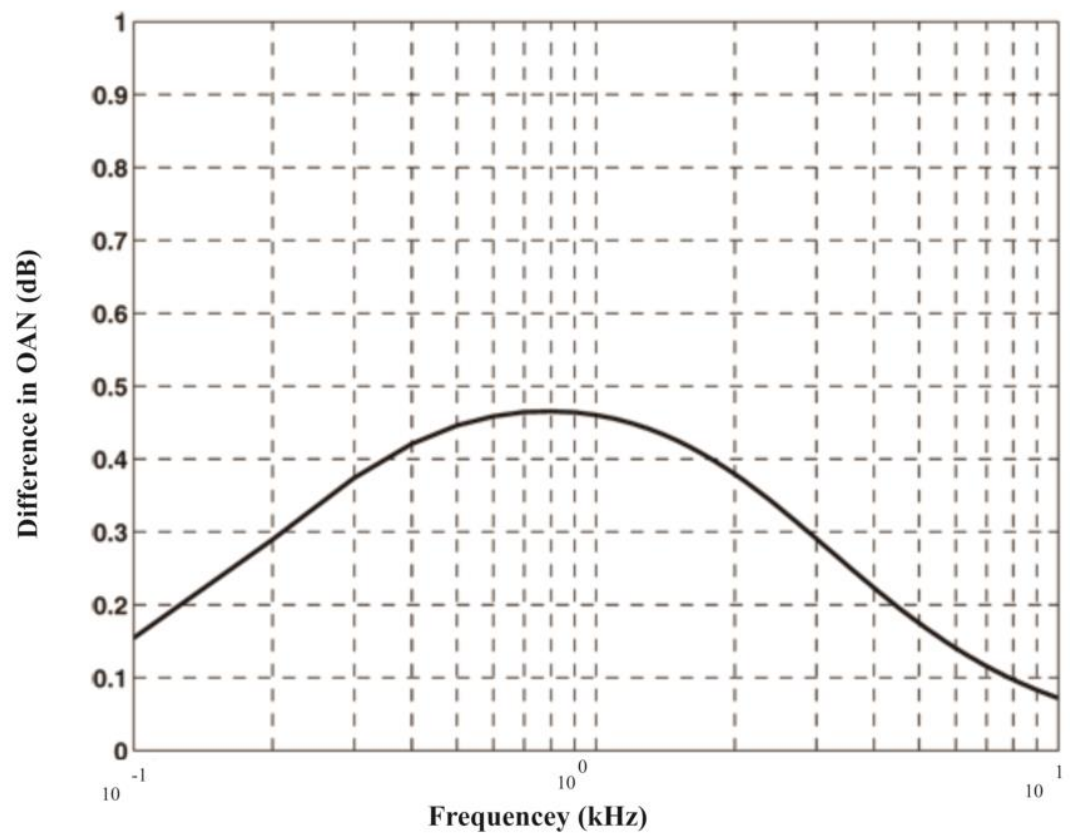

Fig.6. Expected variance in average ambient noise level $(\mathrm{dB})$ for the deep water case using the historical $\mathrm{pH}$ profile from the 1960's (Browning et al., 1988) and a predicted $\mathrm{pH}$ profile for the year 2250 (Caldiera and Wickett, 2003). An increase of $0.5 \mathrm{~dB}$ is a statistically minor change associated to the critical unpredictability of OAN associated with shipping and anthropogenic activities (Reeder and Chiu, 2010).

Anthropogenic $\mathrm{CO}_{2}$ enters into the deep ocean; the changes in sound absorption will also propagate well underneath the deep sound channel axis. Sound absorption will continue to decrease even after reductions in $\mathrm{CO}_{2}$ emissions because ocean $\mathrm{pH}$ will continue to decrease. Sound absorption will continue to decrease even after reductions in $\mathrm{CO}_{2}$ emissions because 
ocean $\mathrm{pH}$ will continue to decrease (Ilyina, et al., 2009). A decrease in $\mathrm{pH}$ by about 0.45 units results in a decrease in sound absorption by about $\% 50$ for frequencies below about $1 \mathrm{kHz}$. As a result, sound could have to travel at least twice as far to lose the same amount of energy to absorption in LFB.

The scale of surface ocean $\mathrm{pH}$ change today from the +105 ppmv change in atmospheric $\mathrm{CO}_{2}$ is about $-0.12 \mathrm{pH}$ units, sound absorption will be more than $\% 12 \pm \% 3$. Under reasonable projections of future fossil fuel $\mathrm{CO}_{2}$ emissions, $\mathrm{pH}$ change of 0.4 units or more could be expected by mid-century, resulting in a decrease by approximately $40 \%$ (Herster, et al., 2008). Other investigations modelled that effect of the increasing acidity of the ocean would have OAN levels in shallow water where the internal waves are exist. (Rouseff and Tang, 2010). The $\mathrm{pH}$ units decreased from 8.0 to 7.4 caused increasing about one decibel OAN. (Fig. 6). These results are representative of other contemporaneous investigations dealing this subject (Rouseff and Tang, 2010; Etter, 2012). A insignificant variation in OAN in the deep waters for all frequencies well known acoustic features.

Physicochemical and mathematical calculations show us a drop of 0.1 of $\mathrm{pH}$ of seawater, acidity is estimated to have increased by $27 \%$ (Barry, 20110). Rendering to introduction to oceanography, global $\mathrm{pH}$ is 8.2 globally which is the first obtained knowledge of chemical oceanography over the last decades. The average $\mathrm{pH}$ of seawater has declined from 8.19 to 8.05 .

\section{Conclusion}

The oceans are now undergoing extreme conditions in their fundamental chemical state and at a proportion not observed before and the effects are being converted not only biological, physical and geological oceanography but also ocean acoustics. The oceans are known as significant carbon reservoir. Scientific knowledge of interactions between changes of the oceans $\mathrm{pH}$ and concentration of $\mathrm{CO}_{2}$ in atmosphere and their effects are currently limited. Both OAc and climate change result from increasing atmospheric $\mathrm{CO}_{2}$ emissions.
Effects of climate change, mainly increases in ocean temperature, will directly impact on marine ecosystems. According to calculation and estimation it is currently taking up about 1 ton anthropogenic $\mathrm{CO}_{2}$ per year for each human by oceans. A half of the $\mathrm{CO}_{2}$ produced has been absorbed by the oceans since industrial revolution. Calculations based on measurements of the surface oceans and according to scientific knowledge of ocean chemistry, indicate that this uptake of $\mathrm{CO}_{2}$ has reduced surface seawater $\mathrm{pH}$ by approximately $0.1 \pm 0.001$ units, which corresponds to an increase of approximately $\% 30$ in the concentration of $\mathrm{H}$ ions. Nowadays, $\mathrm{pH}$ of ocean is 8.1 (over the last 400 million years, $\mathrm{pH}$ is stable 8.2) which shows us that the dramatic changes have been taking place in oceans globally. Environmental condition of the oceans has high rate of acceleration than any change in acidity of seawater known last period of Earth's life hosting. More than the estimated marine life forms it is estimated that, quickly adaptions to changes occurred in the oceans acidity. Although in danger of assuming the OAc, oceans would not become acidic. Additionally, OAc likely will affect the biogeochemical dynamics of ocean (calcium carbonate, organic carbon, nitrogen, and phosphorus) as well as the seawater chemical, physical and biological features.

Carbon dissolves which into the ocean is caused more acidic condition in oceans which has a strong connection between ocean chemistry and sound propagation. Declining sound absorption due to changes in ocean chemical composition is obvious. As the ocean becomes more acidic, sound absorption at 10 to $500 \mathrm{~Hz}$ (low frequency bands) decreases and acidic oceans would result in significant decreases in ocean sound absorption and sounds would propagate farther, making the ocean noisier, and it would have to travel at least twice as far to lose the same amount of energy to absorption at 10 to $500 \mathrm{~Hz}$.

Trends show us noise pollution has been getting worse, $\mathrm{CO}_{2}$ has been rising; and this results an additional increase of OAN. However decreasing sound absorption, underwater sound could travel farther and this could generate OAN. Low-frequency sounds could also enable 
marine mammals to communicate over longer distances. More knowledge about impacts of $\mathrm{pH}$ and sound relation in ocean acoustics need to be further investigations. Some investigation suggested (Joseph and Chiu, 2010; Reeder and Chiu, 2010) that OAN levels in the ocean are very insensitive to the OAc. However the sounds of the sea have less mysterious than they had a few years ago, but also underwater acoustic knowledge is still limited to learn and sense which sounds different underwater creatures could actually hear.

Salinity has a much smaller effect on sound speed than temperature or pressure at most locations in the ocean, anthropogenic influences are changing the oceans chemistry which affects the sound propagation in oceans. As a result of the decline in attenuation by absorption due to OAc which is the significant factor for temperature increase and $\mathrm{pH}$ decrease, the OAN levels are expected to increase in the surface and shallow ocean layers $(>500 \mathrm{~m})$. According to calculation and estimation, OAN seems to be growing by about 3 to 5 decibels per decade in the band occupied by activity and effects of OAc in deep waters of oceans. Rising OAN is going to influence marine life forms by interfering with their ability to detect sounds, also might cause comprehensive stress and affect developmental, reproductive, or immune functions. Effects on marine life due to these changes are expected and dynamically investigated. Biological processes such as calcification and respiration

\section{References}

Barry, J.P. 2010. Marine organisms and ecosystems in a high- $\mathrm{CO}_{2}$ ocean and an overview of recommendations from the national research council's committee report on development of an integrated science strategy for ocean acidification monitoring, research, and impacts assessment. Statement for consideration by Subcommittee on Oceans, Atmosphere, Fisheries, and Coast Guard of the Committee on Commerce, Science, and Transportation United States Senate. of deep-sea animals are already expected to be negatively affected. Ocean acidification is leading to changes in the geophysical properties of the ocean as well. Ocean acidification needs a detailed investigation (such as carbonate chemistry, etc.). Underwater acoustic is one of the most important features and should be investigated in the area under the pressure of OAc. Underwater acoustic is not only important for fish and mammals but also important for humanity who works in underwater engineering, wireless network and naval forces, etc. Briefly summarize; more $\mathrm{CO} 2$ in the atmosphere means a noisier ocean and increases in OAc are already assisting sound to travel further.

Elevation of ocean alkalinity and OAN are global environmental problem which is strongly responsible from the global climate change and the ratio of $\mathrm{CO}_{2}$ concentration of atmosphere. International organizations have begun to address the problem of sound propagation due to OAc, urging that nations work together. The recent years it has seen a remarkable increase in awareness of OAN as an issue that must be addressed multilaterally. The understanding of OAc and its impacts needs to be investigated by the international scientific institutions (IPCC, IOC, IMO, etc.) which must be supported longterm records and measurements in diverse marine environments. This will help to document the past changes in OAN besides to provide a baseline for future changes.

Bass A.H. and McKibben J.R. 2003. Neural mechanisms and behaviors for acoustic communication in teleost fish. Prog Neurobiol 69:1-26.

Brewer, P. G., and J. C. Goldman 1976, Alkalinity changes generated by phytoplankton growth, Limnol. Oceanogr., 21: $108-117$.

Brewer, P. G., D. M. Glover, C. Goyet, and D. K. Shafer. 1995. The $\mathrm{pH}$ of the North Atlantic Ocean: Improvements to the global model for sound absorption in seawater, J. Geophys. Res., 100: 8761-8776. 
Browning, D. G., Scheifele, P. M., and Mellen, R. H., (1988). "Attenuation of low frequency sound in ocean surface ducts: Implications for surface loss values," NUSC TM, p. 318-322.

Caldiera, K., and Wickett, M. E. (2003). "Anthropogenic carbon and ocean $\mathrm{pH}$," Nature (London): 425, 365p.

Canadell, J.G., and Que're', C.L., Raupacha, M.R., Fielde, C.B., Buitenhuisc, E.T., Ciaisf, P., Conwayg, T.J., Gillett, N.P., Houghton, R.A., and Marlandi, G. 2007. Contributions to accelerating atmospheric $\mathrm{CO} 2$ growth from economic activity, carbon intensity, and efficiency of natural sinks, PNAS, Vol 104 (47): 18 866-18 870.

Collins, S., Rost, B., Rynearson, T. A. 2014. Evolutionary potential of marine phytoplankton under ocean acidification. Evolutionary Applications, 7: 140-155.

Doney, S. C., N. Mahowald, I. Lima, F. T. Mackenzie, J.-F. Lamarque, and P. J. Rausch. 2007. Impact of anthropogenic atmospheric nitrogen and sulfur deposition on ocean acidification and the inorganic carbon system, Proc. Natl. Acad. Sci. U. S. A., 104(37): 14 580- 14585.

Etter, P.C. 2012. Advanced Applications for Underwater Acoustic Modeling, Advances in Acoustics and Vibration Vol. 2012: 28p.

Feely, R. A., Doney, S. C., Cooley, S. R. 2009. Ocean acidification: present conditions and future changes in a high- $\mathrm{CO} 2$ world. Oceanography 22:36-47.

Feely, R.A., Takahashi, T., Wanninkhof, R., McPhaden, M. J., Cosca, C. E. and Sutherland, S. C. 2006. Decadal variability of the air-sea $\mathrm{CO} 2$ fluxes in the equatorial Pacific Ocean, 111 (C8), DOI. 10.1029/2005JC003129

Fisher, F. H., and V. P. Simmons. 1977. Sound absorption in sea water, J. Acoust. Soc. Am., 62: 558-564.

Friedlingstein, P., Cox, P., Betts, R., Bopp, L., Von Bloh, W., Brovkin, V., Cadule, P., Doney, S., Eby, M., Fung, I., Bala, G., John, J., Jones, C., Joos, F., Kato, T., Kawamiya, M., Knorr, W., Lindsay, K., Matthews, H.
D., Raddatz, T., Rayner, P., Reick, C., Roeckner, E., Schnitzler, K. G., Schnur, R., Strassmann, K., Weaver, A. J., Yoshikawa, C. and Zeng, N. 2006. Climate-carbon cycle feedback analysis: Results from the C*MIP model intercomparison. Journal of Climate 19(14):3 337-3 353.

Hall-Spencer, Jason M., Riccardo RodolfoMetalpa, Sophie Martin, Emma Ransome, Maoz Fine, Suzanne M. Turner, Sonia J. Rowley, Dario Tedesco, and Maria-Cristina Buia. 2008. Volcanic Carbon Dioxide Vents Show Ecosystem Effects of Ocean Acidification." Nature 454, no. 7200: 96-99.

Halpern, B. S., Walbridge, S., Selkoe, K. A., Kappel, C. V., Micheli, F., D'Agrosa, C., Bruno, J. F., Casey, K. S., Ebert, C., Fox, H. E., Fujita, R., Heinemann, D., Lenihan, H. S., Madin, E. M. P., Perry, M. T., Selig, E. R., Spalding, M. and Steneck, R. 2008. A Global map of human impact on marine ecosystems. Science 319: 948-952.

Hester, C.K. Peltzer, E. T., Kirkwood, W.J and Brewer, P.G. 2008. Unanticipated consequences of ocean acidification: A noisier ocean at lower $\mathrm{pH}$, Geophysical Research Letters, Vol. 35: 1-5.

Hildebrand, J.A. 2009, Anthropogenic and natural sources of ambient noise in the ocean. Mar. Ecol. Prog. Ser. Vol.395:5-20.

Ilyina, T., R. E. Zeebe, and P. G. Brewer. 2009. Future ocean increasingly transparent to low-frequency sound owing to carbon dioxide emissions. Nature Geoscience. Advance Online Publication 2009.

IPCC 2005. "IPCC Special Report on Carbon Dioxide Capture and Storage" 390p.

Jacobson, M. Z. 2005. Studying ocean acidification with conservative, stable numerical schemes for nonequilibrium airocean exchange and ocean equilibrium chemistry. Journal of Geophysical Research Atmospheres $\quad 110$ DOI:10.1029/2004JD005220.

Joseph, J.E. and Chiu, C. 2010. "A computational assessment of the sensitivity of ambient noise level to ocean acidification". J Acoust Soc Am. 128(3), DOI: $10.1121 / 1.3425738$. 
Ketten, D. R., and D. Wartzok. 3-Dimensional Reconstructions of the Dolphin Ear. Sensory Abilities of Cetaceans: Laboratory and Field Evidence. edited by J. A. Thomas and R. A. Kastelein. Vol. 196,1990.

Kira, C. 2014. Expect the Unexpected: Acidic Oceans, Marine Tech. Reporter, March 2014:46-51.

Kuperman W.A. 1988. Propagation effects associated with ambient noise. In: Kerman BR (ed) Sea surface sound: natural mechanisms of surface generated noise in the ocean. Kluwer, Dordrecht, :253-272

Lo Monaco, C., Metzl, N., Poisson, A., Brunet, C. and Schauer, B. 2005. Anthropogenic $\mathrm{CO} 2$ in the Southern Ocean: Distribution and inventory at the Indian-Atlantic boundary (World Ocean Circulation Experiment Line line I6), Journal of Geophysical Research, 110:1-18.

Lüthi, D., M. Le Floch, B. Bereiter, T. Blunier, J.-M. Barnola, U. Siegenthaler, D. Raynaud, J. Jouzel, H. Fischer, K. Kawamura, and T.F. Stocker. 2008. High-resolution carbon dioxide concentration record 650,000800,000 years before present. Nature 453:379-38

Raven J., C., Elderfield, H., Hoegh-Guldberg, O., Liss, P., Riebesell, U., Shepherd, J., Turley, C and Watson, A. 2005. Ocean acidification due to increasing atmospheric carbon dioxide. Royal Society, London, UK: 68p.

Raven, J. A. and Falkowski, P. G. 1999. Oceanic sinks for atmospheric CO2.. Plant, Cell and Environment 22 (6): 741-755.

Redfield A.C. 1934. On the proportions of organic derivations in sea water and their relation to the composition of plankton. In James Johnstone Memorial Volume. (ed. R.J. Daniel). University Press of Liverpool, pp. 177-192.

Reeder D.B. and Chiu, C.S. 2010. "Impact of acidification on ocean noise." J. Acoust. Soc. Am. 128 (3).

Richardson WJ, Greene CRJ, Malme CI, Thomson D.H. 1995. Marine mammals and noise. Academic Press, San Diego, CA.
Ross, 1993. On Ocean Underwater Ambient Noise. Institute of Acoustics Bulletin, St Albans, Herts, UK: Institute of Acoustics, 18.

Rouseff, D. and Tang, D. 2010. Internal waves as a proposed mechanism for increasing ambient noise in an increasingly acidic ocean. Journal of the Acoustical Society of America, vol. 127 (6) pp.235-239.

Sabine, C.L., and R.A. Feely. 2007. The oceanic sink for carbon dioxide. Pp. 31-49 in Greenhouse Gas Sinks. D. Reay, N. Hewitt, J. Grace, and K. Smith, eds, CABI Publishing, Oxfordshire, UK.

Simpson SD, Meekan M, Montgomery J, McCauley R, Jeffs A. 2005. Homeward sound. Science 308:221.

Turley, C., Blackford, J., Widdicombe, S., Lowe, D., Nightingale, P.D. and Rees, A.P. 2006. Reviewing the impact of increased atmospheric $\mathrm{CO} 2$ on oceanic $\mathrm{pH}$ and the marine ecosystem. In: Avoiding Dangerous Climate Change. Schellnhuber, H J., Cramer, W., Nakicenovic, N., Wigley, T. and Yohe, G. (Eds). Cambridge University Press, 8, 65-70.

Wallace, D.W.R. 2001. Introduction to special section: Ocean measurements and models of carbon sources and sinks, Global Biogeochemical Cycles, 15, 3-10.

Waugh, D.W., Hall, T.M., Mcneil, B. And Key, R. 2006. Anthropogenic CO2 in the oceans estimated using transit-time distributions, Tellus B, 58, 376-389. 